\title{
Colon or Rectum Neuroendocrine Tumor pN1 TNM Finding v7
}

National Cancer Institute

\section{Source}

National Cancer Institute. Colon or Rectum Neuroendocrine Tumor pN1 TNM Finding v7. NCl Thesaurus. Code C90112.

Colon or rectum neuroendocrine tumor with regional lymph node metastasis. (from AJCC 7th Ed.) 